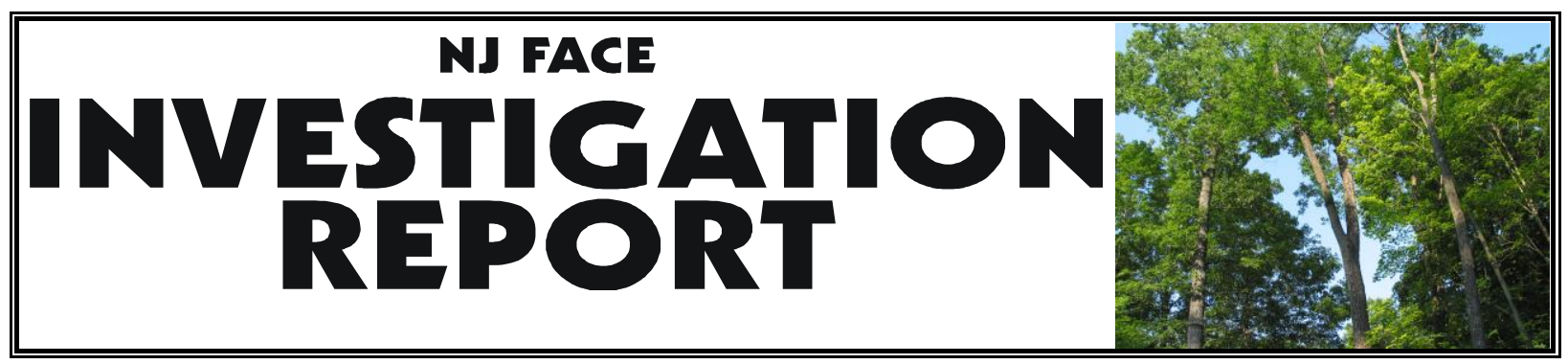

Fatality Assessment \& Control Evaluation Project

FACE 12-NJ-019

August 21, 2013

\title{
Twenty-seven-year-old Tree-care Worker Killed by Falling Branch
}

A 27-year-old male ground crewman at a tree care company was struck and killed by a 38-pound cut branch. On the day of the incident, the decedent and two other workers were felling an approximately 80-foot tall ash tree on a farm in northern New Jersey. One worker was cutting branches from about 60 feet up in the tree and the other two workers were on the ground using chainsaws and a wood chipper to process felled branches. The worker in the tree signaled to the two below that a branch was about to be cut (free-fall cut, not a controlled descent). Both ground crew members were standing near the chipper and had acknowledged the signal. For an unknown reason, one of the ground crew members began walking towards the drop zone and was struck and killed by the falling branch.

Contributing Factors

- Delineation of drop zone

- Noise from the wood chipper

- Communication

NJ FACE investigators recommend that these safety guidelines be followed to prevent similar incidents:

- A clear delineation of the drop zone (also known as exclusion zone or drip zone) should be created using spray paint or tape.

- Ensure that proper communication exists in or around the drop zone.

- Whenever possible, pile all branches to be pruned or chipped in the same location, out of the drop zone.

- A safety and health plan based on a job hazard analysis should be developed by the employer and followed where workers are assigned tasks.

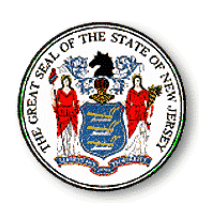

Public Health Services Branch Division of Epidemiology, Environmental and Occupational Health Occupational Health Surveillance Unit (609) 826-4984 nj.gov/health/surv/face/index.shtml 


\section{INTRODUCTION}

In summer of 2012, NJ FACE staff was notified of the death of a 27-year-old male tree care worker who was killed when he was struck by a felled branch on a farm in Northern NJ. The victim had worked for the tree company for approximately two years. Employee health and safety training, as well as job training, was conducted on site by the employer.

A NJ FACE investigator contacted the OSHA Area Office and conducted the investigation. Additional information was obtained from the medical examiner's report, death certificate, OSHA, and the police report.

\section{INVESTIGATION}

The day of the incident was warm (approximately $85^{\circ} \mathrm{F}$ ), with no significant precipitation recorded. The incident occurred in a heavily wooded area of a private farm/residential community. The tree care company was hired to fell several trees on the property, most of which were tall "forest" trees (long trunks with few branches until the top portion).

Three employees of the tree company were assigned to the site on the day of the incident. One worker was designated as the climber (worker \#1), whose job was to work in the tree cutting branches. The two other workers (worker \#2 and \#3), including the deceased (worker \#2), functioned as ground crew. They were tasked with trimming and chipping felled branches and assisting the worker in the tree on controlled descents of cut branches. Controlled descents were conducted when there were physical obstructions or hazards to the free fall of a cut branch, and were accomplished by using a rope and pulley system. All branches that were cut above the power lines or the residence were felled using a controlled descent (pulley and rope mechanism) (Figure 1). The remaining cuts were free-fall cuts, including the one involved in the incident.

The incident scene is depicted in Figure 2. There was a residence on the east side of the tree to be felled. The power lines and a narrow gravel road were located to the south of the tree. At the time of the incident, the chipper was located approximately 28-feet away from the tree on the south side of the road. The decedent's assigned pruning saw was located west of the tree and the exclusion zone on the side perpendicular to the chipper, across the drop zone. On the north side of the tree was a pile of brush, branches, and tree top that was already roped and staged and ready to be chipped. Plastic orange cones were placed on the ground underneath the power lines to mark their location to worker \#1 in the tree above. 
At the time of the incident, the tree was nearly trimmed of all branches, with one remaining large branch. Workers \#2 and \#3 were at the chipper loading some brush (the chipper was running). The tree had been topped, and as mentioned earlier, many branches were piled on the north side of the tree. Worker \#1 was ready to cut the remaining branch (approximately 4.5 " in diameter, $38.2 \mathrm{lbs}$ ), and obtained eye contact with the ground crew at the chipper. He signaled to them with his pointer finger, "one more." According to worker \#3, communication was established between the worker in the tree, himself, and the deceased (it was a combination of hand signals and verbal communication). At this point, worker \#1 began the cut, which went as planned. For an unknown reason, the deceased began walking towards the exclusion zone. It is believed that he began walking towards the work he still needed to finish, i.e., the branches and tree top on the north side of the tree. As he was walking, he turned west (left) possibly to retrieve his pruning saw, which placed him directly under the falling branch.

Figure 1. Power lines on site, similar to the tree involved in the incident; note the height of the power lines with respect to the tree (any branches above would have to be felled using controlled descent).

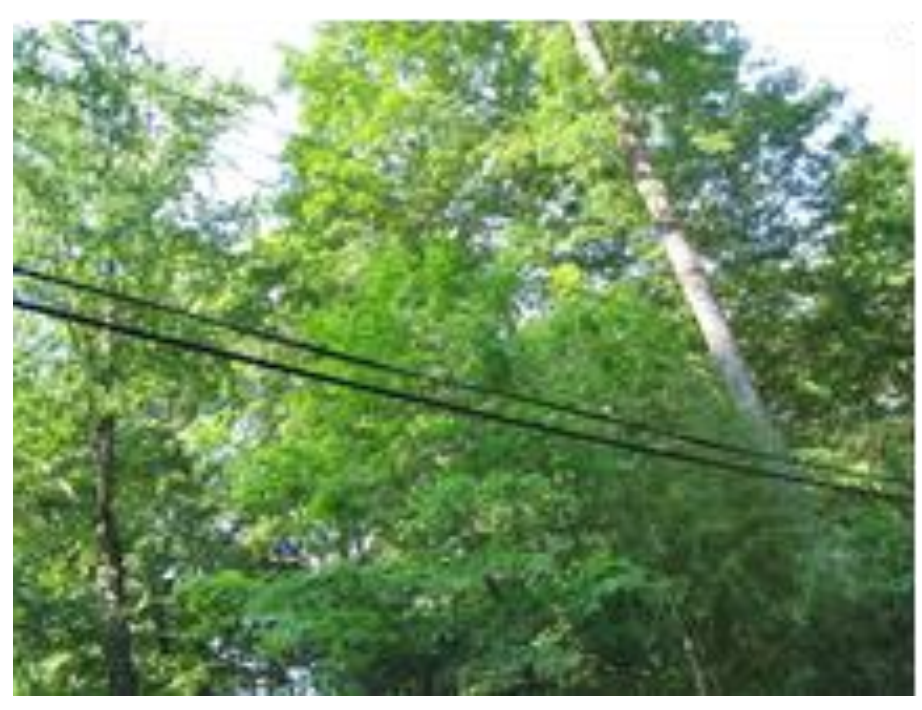


Figure 2. Incident site (not to scale).

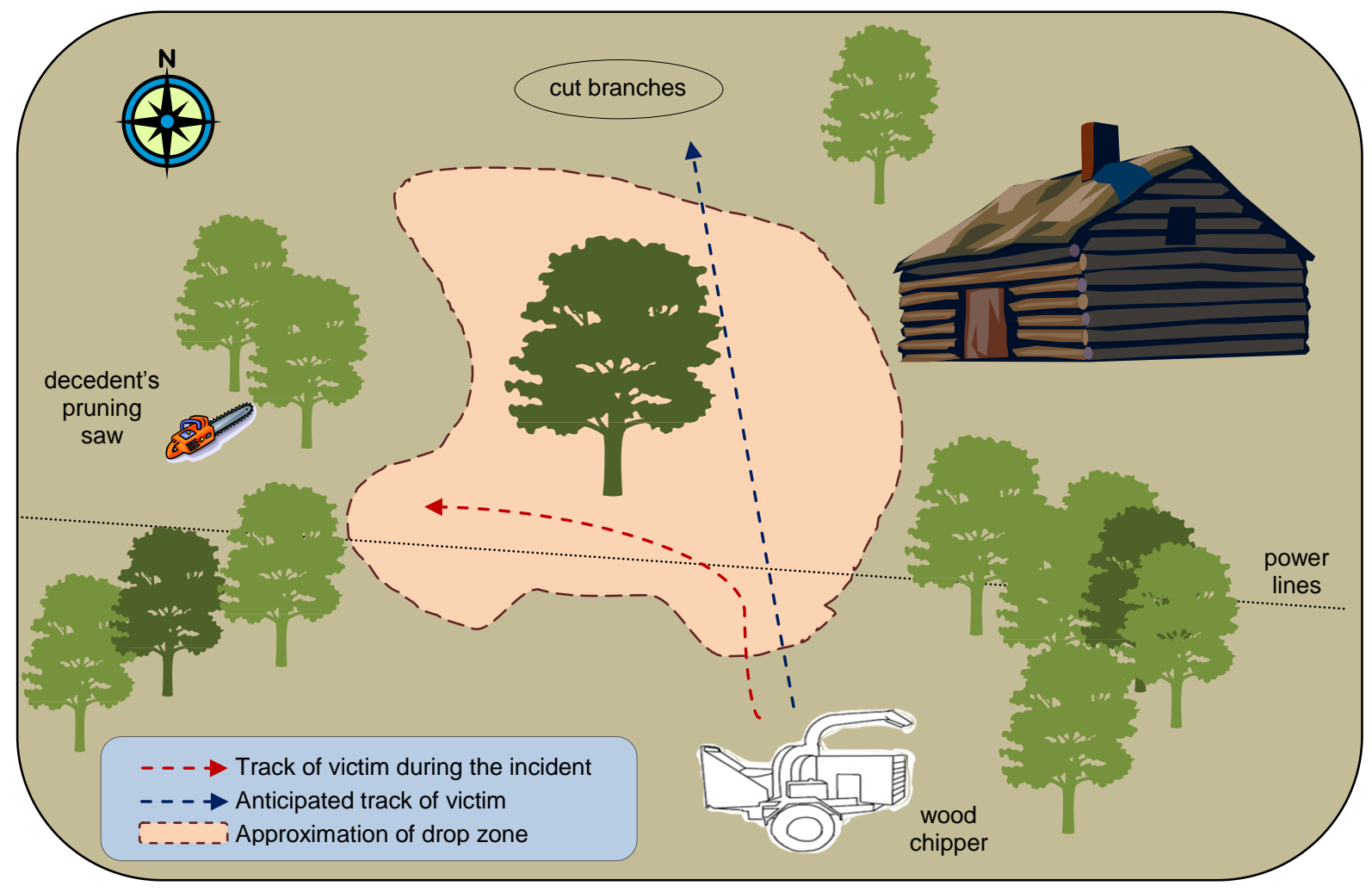

Recommendation \#1: A clear delineation of the drop zone (also known as exclusion zone or drip zone) should be created using spray paint or tape.

\section{Discussion:}

As per ANSI Z133.1-2006, a work zone shall be established prior to any rigging operations, and workers not directly involved shall stay out of this work zone until communicated that it is safe to enter. ${ }^{1}$ In addition, we recommend that this drop zone be uniform in shape (see Figure 3), and marked in a way that is apparent to all workers. A "visual drop zone" can be adequately created using brightly colored spray paint or tape. 
FIGURE 3: Approximation of drop zone on site (left) vs. recommended drop zone $(\triangle=$ tree $)$
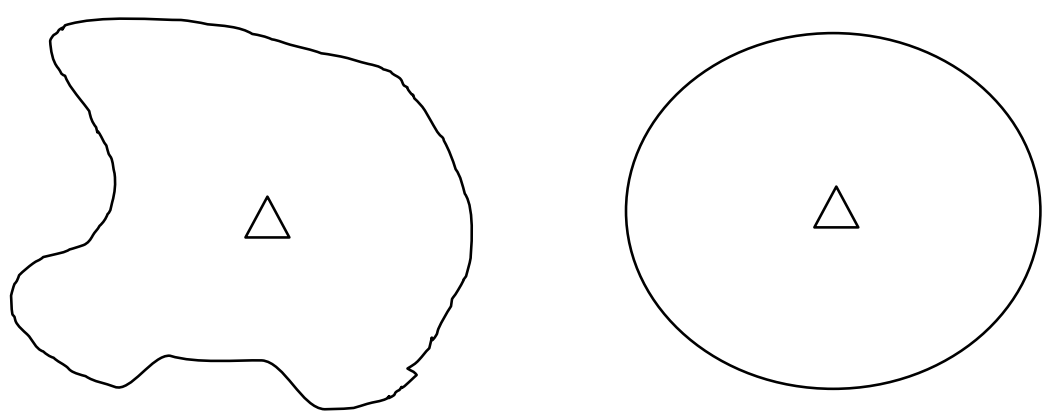

Recommendation \#2: Ensure that proper communication exists in or around the drop zone. Discussion:

A method of communication should be discussed and established prior to the start of tree care operations. ${ }^{2}$ As per ANSI Z133.1-2006, this system shall use a command and response system or a set of prearranged hand signals. ${ }^{2}$ An additional method of communication could include two-way radio, but this may be subject to interferences from noises inherent in the work. The employer in this case had an established communication program under which all employees were trained. In this incident, there was a combination of both hand signals and verbal communication and it could not be agreed upon afterwards exactly which set of instructions were used. A pre-job meeting should be held to clarify and confirm the communication system to be used.

In addition, at the time of the incident, the wood chipper was running. NJ FACE recommends that when a potentially hazardous cutting is taking place, any auxiliary operation that could interfere with communication during tree care operations should be avoided.

\section{Recommendation \#3: Whenever possible, pile all branches to be pruned or chipped in the same} location, out of the drop zone.

Discussion: In this case, the employee had to cross the drop zone to complete his assigned task. NJ FACE recommends that if possible, pile all cut branches to pruned or chipped in one safe location to minimize the chance that a worker crosses into the drop zone.

Recommendation \#4: A safety and health plan based on a job hazard analysis should be developed by the employer and followed where workers are assigned tasks. 
Discussion: Employers should conduct a job hazard analysis, with the participation of employees, of all work areas and job tasks. A job hazard analysis should begin by reviewing the work activities for which the employee is responsible, and the equipment that is needed. Each task is further examined for mechanical, electrical, chemical, or any other hazard the worker may encounter. A source of information on conducting a job hazard analysis is included in the Appendix. ${ }^{3}$ 


\section{APPENDIX}

\section{RECOMMENDED RESOURCES}

It is essential that employers obtain accurate information on health, safety, and applicable OSHA standards. NJ FACE recommends the following sources of information which can help both employers and employees:

\section{U.S. Department of Labor, Occupational Safety \& Health Administration (OSHA)}

Federal OSHA can provide information on safety and health standards on request. OSHA has several offices in New Jersey that cover the following counties:

第 Hunterdon, Middlesex, Somerset, Union, and Warren counties....................732-750-3270

Essex, Hudson, Morris, and Sussex counties.................................................973-263-1003

解 Bergen and Passaic counties.....................................................................201-288-1700

Atlantic, Burlington, Cape May, Camden, Cumberland, Gloucester,

Mercer, Monmouth, Ocean, and Salem counties......................................856-757-5181

Web site: www.osha.gov

\section{New Jersey Public Employees Occupational Safety and Health (PEOSH) Program}

The PEOSH Act covers all NJ state, county, and municipal employees. Two state departments administer the Act; the NJ Department of Labor and Workforce Development (NJDLWD), which investigates safety hazards, and the NJ Department of Health (NJDOH) which investigates health hazards. PEOSH has information that may also benefit private employers.

NJDLWD, Office of Public Employees Safety

然Telephone: 609-633-3896

Web site: www.nj.gov/labor/lsse/lspeosh.html

NJDOH, Public Employees Occupational Safety \& Health Program

籍Telephone: 609-984-1863

Web site: www.nj.gov/health/peosh

On-site Consultation for Public Employers

雨Telephone: 609-984-1863 (health) or 609-633-2587 (safety)

Web site: www.state.nj.us/health/eoh/peoshweb/peoshcon.htm 
New Jersey Department of Labor and Workforce Development, Occupational Safety and Health On-Site Consultation Program

This program provides free advice to private businesses on improving safety and health in the workplace and complying with OSHA standards.

留Telephone: 609-984-0785

Web site: www.nj.gov/labor/lsse/lsonsite.html

\section{New Jersey State Safety Council}

The New Jersey State Safety Council provides a variety of courses on work-related safety. There is a charge for the seminars.

留Telephone: 908-272-7712.

Web site: www.njsafety.org

\section{Internet Resources}

Other useful Internet sites for occupational safety and health information:

- $\mathrm{CDC} / \mathrm{NIOSH}-w w w . c d c . g o v / n i o s h$

- USDOL Employment Laws Assistance for Workers and Small Businesses - www.dol.gov/elaws

- National Safety Council - www.nsc.org

- NJDOH FACE reports - www.nj.gov/health/surv/face/index.shtml

- CDC/NIOSH FACE - www.cdc.gov/niosh/facelfaceweb.html

- OSHA - www.osha.gov

- ANSI - www.ansi.org

\section{REFERENCES}

1. American National Standards Institute (ANSI), American National Standard for Arboriculture Operations-Safety Requirements; Z133.1-2006; 8.4.12, page 24.

2. American National Standards Institute (ANSI), American National Standard for Arboriculture Operations-Safety Requirements; Z133.1-2006; 8.4.11, page 24.

3. Job Hazard Analysis. US Department of Labor Publication \# OSHA-3071, 1998 (revised). USDOL, OSHA Publications, PO Box 37535, Washington DC 20013-7535 


\section{Fatality Assessment and Control Evaluation (FACE) Project Investigation \# 12-NJ-19}

This report was prepared by staff members of the New Jersey Department of Health's Occupational Health Surveillance Unit. The goal of FACE is to prevent fatal work-related injuries by studying the work environment, the worker, the task, the tools the worker was using, the energy exchange resulting in the fatal injury, and the role of management in controlling how these factors interact. FACE gathers information from multiple sources that may include interviews of employers, workers, and other investigators; examination of the fatality site and related equipment; and reviewing OSHA, police, and medical examiner reports, employer safety procedures, and training plans. The FACE program does not determine fault or place blame on employers or individual workers. Findings are summarized in narrative investigation reports that include recommendations for preventing similar events. All names and other identifiers are removed from FACE reports and other data to protect the confidentiality of those who participate in the program.

NIOSH-funded state-based FACE Programs include: California, Iowa, Kentucky, Massachusetts, Michigan, New Jersey, New York, Oregon, and Washington. Please visit the NJ FACE Web site at www.nj.gov/health/surv/face/index.shtml or the CDC/NIOSH FACE Web site at www.cdc.gov/niosh/face/faceweb.html for more information.

The NJ FACE Project is supported by the Centers for Disease Control and Prevention (CDC). The contents of this report are solely the responsibility of the authors and do not necessarily represent the official views of the CDC.
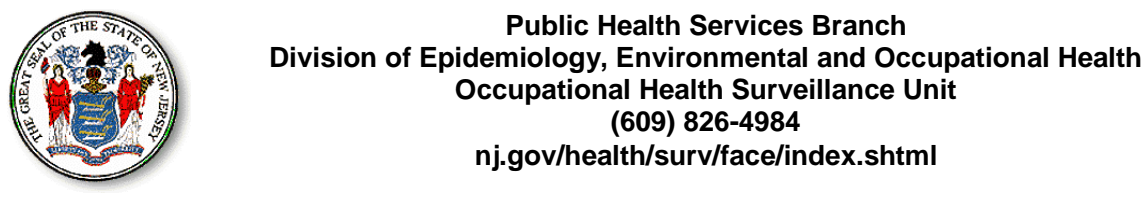